\title{
VARIAÇÃO DA ERODIBILIDADE DO SOLO DURANTE O ANO
}

\author{
RICARDO SIMAOO AMON \\ Engenheiro Agrônomo
}

Orientador: Dr . FRANCISCO LOMBARDI NETO

Dissertação apresentada à Escola Superior de Agricultura "Luiz de Queiroz", da Universidade de São Paulo, para a obtenção do título de Mestre em Agronomia, Area de Concentração: Solos e Nutrição de Plantas.

\author{
P I RAC I CABA \\ Estado de São Paulo - Brasil \\ Janeiro - 1994
}


Ficha catalografica preparada pela Seça de Livros da Divisăo de Biblioteca e Documentaça - FCLQ/USP

\footnotetext{
Amon, Ricardo Simaro Q⿱一夕卜l

A523v Variaça da erodibilidade do 5010 durante a ano. Firacicaba, 1994. $46 \mathrm{p}$.

Diss. (Mestre) - ESALQ

Bibliografia.

1. Erosâo - Estimativa - Modelo matematico 2. Solo Erodibilidade I. Escola Superior de Agricultura Luic de Queiroz, Piracicaba
} 


\section{VARIAÇÃO DA ERODIBILIDADE DO SOLO DURANTE O ANO}

Aprovada em: $07 / 03 / 1994$

Comissão Julgadora:

Dr. Francisco Lombardi Neto 
i i i .

Aos meus pais,

Jorge e Georgete

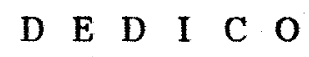

A minha esposa, Regina

A minha filha, Maria Clara

O F E R E C O 


\section{AGRADEC IMENTOS}

Ao Dr. Francisco Lombardi Neto, pela orientação deste trabalho.

Ao Professor Dr. Geraldo Victorino de França, pela coordenação do curso de pós-graduação e pelas disciplinas de planejamento do Uso da Terra e Fotointerpretação.

Ao Professor Dr. Júlio Vasques Filho, pela disciplina de Conservaçá do solo.

As Seções de Conservaçăo do Solo e de Climatologia Agrícola do Instituto Agronômico do Estado de São Paulo e ao Professor Dr. Morel de Passos e Carvalho, pela gentileza na cessão dos dados.

A Dra. Isabella Clerici De Maria, pelas contribuiçoses ao trabalho e apoio na area de informática.

A Srta. Silvana Cristina Teixeira, pelo apoio na área de informática e preparo do original.

A todos os pesquisadores, funcionarios e estagiarios da Seção de Conservação do Solo do Instituto Agronômico do Estado de são Paulo, pela amizade e incentivo. 
LISTA DE FIGURAS • . . . . . . . . . . . . . . . . . vi .

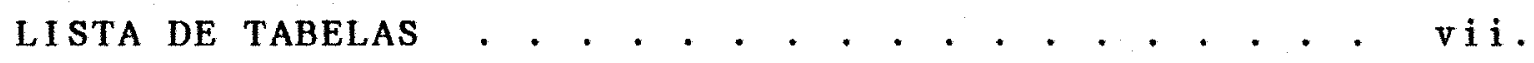

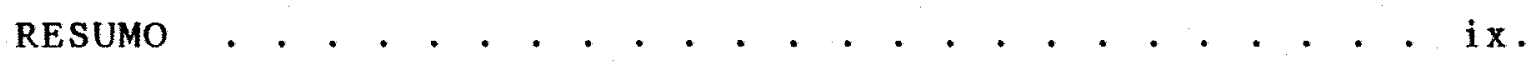
SUMMARY . . . . . . . . . . . . . . . . . . . . . xi.

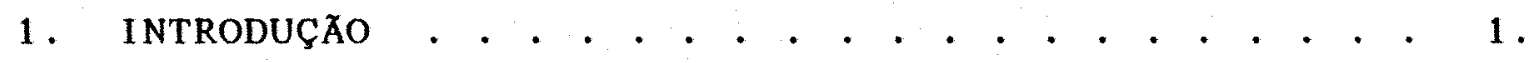

2. REVISAO DE LITERATURA . . . . . . . . . . . . . . 3.

3. MATERIAL E METODOS . . . . . . . . . . . . . . . 12 .

3.1. Material............... . . 12 .

3.2. Métodos . . . . . . . . . . . . . 14 .

4. RESULTADOS • . . . . . . . . . . . . . . 22 .

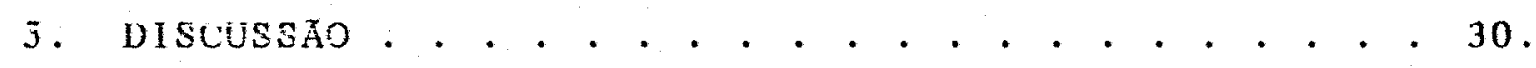

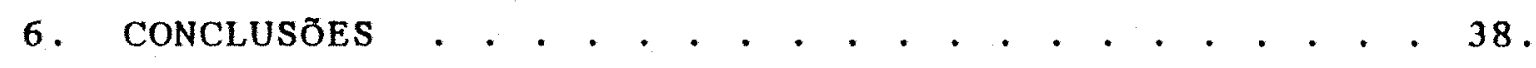

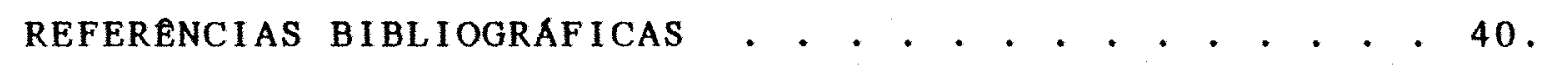




\section{LISTA DE FIGURAS}

Figura

Página

1. Mapa mostrando a localizaça dos municípios

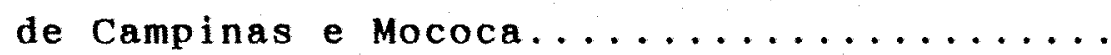

2. Estações do ano baseadas nas Normais Climatológicas de precipitação pluvial e temperatura média do ar (1961-1990)-Campinas

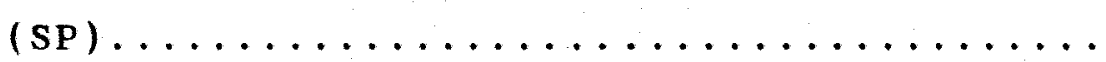

3. Estações do ano baseadas nas Normais Climatologicas de precipitação pluvial e temperatura média do ar (1961-1990)-Mococa

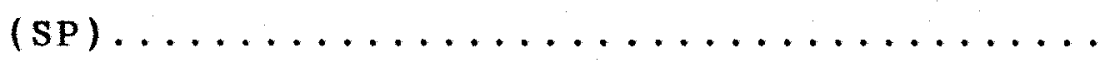

4. Variação da erodibilidade do solo durante o ano, estimada por regressão linear $\operatorname{simples} \ldots \ldots \ldots \ldots \ldots \ldots \ldots \ldots \ldots \ldots$

5. Variação da erodibilidade do solo durante o ano, estimada por $\Sigma A / \Sigma E I_{30} \ldots \ldots \ldots \ldots$ 
vi i .

\section{LISTA DE TABELAS}

Tabe la

Página

1. Atributos do horizonte superficial $(0-20 \mathrm{~cm})$

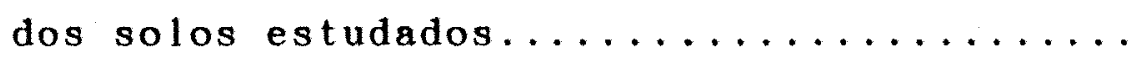

2. Normais Climatológicas de precipitação pluvial e temperatura média do ar para Campinas e Mococa referentes ao periodo de 1961 a

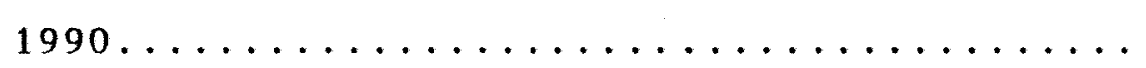

3. Regressões lineares simples e intervalos de confiança ao nível de $5 \%$ da probabilidade para valores de $\mathrm{K}$ médios anual, estacionais e mensais, obtidos a partir de um Latossolo Roxo distrófico em Campinas-sP, no período

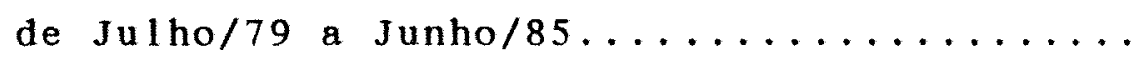

4. Regressões lineares simples e intervalos de confiança ao nível de $5 \%$ de probabilidade para valores de $\mathrm{K}$ médios anual, estacionais e mensais, obtidos a partir de um Podzólico Vermelho-Amarelo eutrófico em Mococa-sp, no período de Julho/79 a Junho/85......... 
5. Precipitação pluvial, EI 30 , perdas de solo e erodibilidade estimada por $\Sigma A / \Sigma E I_{30}$ para um Latogolo Roxo dietrófico em Campinas-sF, no período de Julho/79 a Junho/85.......

6. Precipitação pluvial, EI $I_{30}$, perdas de solo e erodibilidade estimada por $\Sigma A / \Sigma E I_{30}$ para um Podzólico Vermelho-Amarelo eutrófico em Mococa-SP, no período de Julho/79 a Junho $/ 85 \ldots \ldots \ldots \ldots \ldots \ldots \ldots$ 
ix .

\title{
VARIAÇÃO DA ERODIBILIDADE DO SOLO DURANTE O ANO
}

\author{
Autor: RICARDO SIMAOO AMON \\ Orientador: Dr. Francisco Lombardi Neto
}

RESUMO

Com os objetivos de documentar e comparar a variação da erodibilidade durante o ano para dois solos referenciais, um com horizonte B latossólico e outro com horizonte B textural, foram estimados valores anuais, estacionais e mensais correspondentes para o fator $k$ da Equação Universal de Perdas de Solo (EUPS), utilizando-se dados de perdas de solo obtidos em parcelas de campo sob chuva natural.

os métodos correntes para estimativa direta do fator K da EUPS foram comparados, decidindo-se pela superioridade daquele que utiliza a regressão linear simples entre as perdas de solo como variável dependente e o índice de erosividade da chuva-enxurrada como variável independente.

Os resultados indicaram que a erodibilidade do solo varia mensalmente de maneira significativa e diferenciada para os solos testados e, contrariando a literatura oriunda 
da região temperada do globo, tende a ser maior na estação mais seca do ano.

Concluiu-se, também, que o período necessário de duraça dos registros e coleta de dados, para avaliar tendências de longo prazo na erodibilidade do solo, é variável em função da escala temporal que se estiver trabalhando, e pode ser definido pela amplitude desejada dos intervalos de confiança para os valores médios de $K$. 


\title{
SOIL ERODIBILITY VARIATION \\ DURING THE YEAR
}

\author{
Author: RICARDO SIMAOO AMON \\ Adviser: Dr. Francisco Lombardi Neto
}

SUMMARY

In order to document and compare the erodibility variation during the year for two referencial soils, one with an oxic horizon and another with an argillic horizon, correspondent annual, seasonal and monthly values of the $K$ factor of the Universal Soil Loss Equation (USLE) were estimated using soil loss data obtained from field plots under natural rainfall.

The current methods for direct estimation of the USLE $K$ factor were compared and that using simple linear regression between the soil loss as the dependent variable and the rainfal1-runoff index as the independent variable was found superior.

The results indicated that the monthly variation of soil erodibility was significant and differentiated for the soils tested and showed a tendency of being higher in the dry season of the year, although the literature of the temperate 
xii.

region of the globe reports otherwise.

It was also concluded that the necessary period for recording and collecting data to assess long term trends in soil erodibility is a function of the temporal scale of work and may be defined by the desired amplitude of the confidence limits for the average values of $k$. 


\section{INTRODUÇÃO}

A Equação Universal de Perdas de Solo - EuPs (Universal Soil Loss Equation - USLE) é um modelo estatístico preditor da erosão largamente usado. Desenvolvida no início para a região do meio oeste dos Estados Unidos da América, é universal devido ao fato de sua estrutura ser aplicavel globalmente. Seus fatores componentes, que refletem a influência do clima, do solo, da topografia e do uso e manejo praticado em áreas agricultális, podem ser obtidos para qualquer localidade que possua uma base de dados compatínel. Desde a sua apresentação à comunidade cientifica na

década de 1960 , a EUPS vem recebendo adaptações e melhoramentos e, apesar do desenvolvimento recente de modelos físicos baseados em processos compreensiveis, é provavel que continue sendo utilizada, principalmente em função de sua simplicidade.

o modelo EUPS adota, originariamente, uma estimativa média para a erodibilidade de solo, fator $K$, assumindo-a como constante ao longo do ano. Isto é aceitável para prever a média anual da erosa.o. Entretanto, o comportamento do solo quando interagindo com chuvas erosivas varia durante o ano, sendo desejavel estimar valores de $K$ para perlodos de maior 
interesse no contexto de um planejamento conservacionista, como uma estação de chuvas mais intensas ou determinados meses em que se executam operaçóes agrícolas importantes para - controle da erosão, como o preparo do solo, por exemplo.

A importancia de um refinamento temporal do fator $\mathrm{K}$ é realçada quando consideramos a tendência da pesquisa em subdividir o fator $C$ do mesmo modelo, que representa a cobertura e o manejo do solo, detalhando-o atraves de um conjunto de subfatores. Sabe-se que um dos maiores beneficios da EUPS tem sido a possibilidade de esclarecer e exemplificar quantitativamente o valor da conservação do solo para os agricultores, que precisam tomar decisós de cultivo e manejo mais especificas em sua atividade para conseguir atenuar o problema da erosão. Para que se possa estudat e usar efetivamente esta nova configuraça do fator $C$ é necessario adaptar o fator $K$.

Os objetivos do presente trabalho são documentar e comparar a variação da erodibilidade durante o ano para dois solos referenciais, um com horizonte B latossolico e outro com horizonte B textural, estimando valores estacionais e mensais correspondentes para o fator $K$ da EUPS, bem como comparar metodos para sua estimativa. 


\section{REVISAO DE LITERATURA}

A Equação Universal de perdas de Solo permite a tomada de decisoes metódica no planejamento conservacionista de uma determinada área. Algumas vezes esta equaça é utilizada com finalidades para as quais nã foi projetada, simplesmente porque parece atender melhor a uma determinada necessidade do que outras ferramentas disponíveis. Tais extensões de sua aplicação não devem ser categoricamente desencorajadas, mas precauçes apropriadas são necessárias a fim de evitar seu possivel mal emprego ou falsas conclusós (WISCHMEIER, 1976).

Muitas variáveis e interaçōes influenciam a erosão laminar e em sulcos. A Equacão Universal de Perdas de Solo agrupa essas variaveis sob seis fatores principais de erosa cujo produto, para um conjunto particular de condições, estima a perda média anual de solo (WISCHMEIER, 1976). Sua representação (WISCHMEIER \& SMITH, 1978) e conversão para o sistema internacional de unidades (FOSTER et al., 1981) é a seguinte:

$$
A^{\prime}=R \cdot K \cdot L \cdot S \cdot C \cdot P
$$

onde: A é a taxa de perda média anual de solo (t/ha.ano); $R$ é um fator para a erosividade da chuva - 
enxurrada (MJ.mm/ha.h.ano); $\mathrm{K}$ é um fator para a erodibilidade do solo (t.ha,h/ha, MJ.mm); L e S são os fatores topográficos para considerar o comprimento e o grau do declive respectivamente; $C$ é um fator para a cobertura e manejo do solo, e $\mathrm{P}$ é um fator para as praticas conservacionistas de suporte. Os fatores L, S, C e P sao adimensionais.

A equação estima a perda média anual de solo, de longo prazo, para combinações específicas de condições físicas e de manejo. Ela foi projetada para uso a campo por profissionais planejadores da conservaça do solo. Isto requeria facilidade em sua solução e que incluísse apenas os fatores cujos valores, para uma area em particular, pudessem ser determinados a partir dos dados disponiveis. Alguns detalhes e refinamentos em potencial foram sacrificados em benefício de sua utilização prática.

Os valores tabelados para os fatores da equação, obtidos pela pesquisa, compensam em termos médios os efeitos de flutuaçōes ao acaso em muitas das variáveis.

Se os fatores $R$ e $C$ forem apropriadamente selecionados, a estimativa da equaca pode representar a perda média de longo prazo para uma determinada fase de um sistema cultural. A duração do perído considerado na é limitada. Tanto pode ser um ano destacado de uma determinada rotação, comp um estádio de uma cultura. Mas a perda de solo calculada'sera a taxa média estimada para um tempo de recorrencia suficiente para anular os efeitos de curto prazo de variáveis aleatorias e suas interaços com outros fatorea 
(WISCHMEIER, 1976 ).

o fator erodibilidade do solo, $\mathrm{K}$, na Eups, é um valor quantitativo determinado experimentalmente. Para um solo específico, é a quantidade de solo erodida anualmente, medida a partir de uma parcela padrão ou unitária (L.S.C.P = 1), ou ajustada para esta condição, por unidade de erosividade da chuva - enxurrada, ou seja, K iguala-se a A/R (WISCHMEIER \& SMITH, 1965). A erodibilidade é determinada mais acuradamente através de medidas diretas em parcelas de campo, equipadas com tanques coletores de enxurrada, sob chuva natural. Recomenda-se que a tendencia de longo prazo, envolvendo mudanças na erodibilidade com o tempo, seja medida para os solos principais durante um período de 10 a 20 anos (LAL, 1988).

Quando a precipitação atinge um solo relativamente seco, recém preparado, a maior parte da água pode infiltrarse antes que o escorrimento comece, resultando numa baixa perda de solo por unidade de erosividade para aquela chuva. Por outro lado, ao atingir um solo previamente saturado, o escorrimento comeca rapidamente, e a maior parte da chuva transforma-se em enxurada. Tais chuvas geralmente dão origem a uma perda de solo acima do normal. Em um ano pouco chuvoso, a maioria ou todas as chuvas podem incidir sobre um solo seco e receptivo. Já em um ano extremamente úmido, a probabilidade de chuvas erosivas atingirem um solo saturado é muito maior (WISCHMEIER, 1976).

Concluindo sobre a necessidade de se levar em 
consideração as condições de umidade antecedente para estimativas de perdas de solo, DANGLER et al. (1976) acrescentam ainda que esta distinção torna-se ainda mais importante em vista das mudanças que ocorrem nos padröes de agricultura, tais como de não irrigada para irrigada ou de métodos de irrigação de superficie para aspersão, com a suscetibilidade do solo à erosão sendo dependente do regime de umidade predominante sob cada prática.

DANGLER \& EL-SWAIFY (1976) obtiveram valores calculados para o $\mathrm{K}$ médio anual a partir de determinaçóes de $K$, feitas com simulador de chuvas, estando as parcelas inicialmente secas ( $K$ seco) $e$ úmidas ( $K$ úmido). Os resultados indicaram valores de erodibilidade significativamente maiores para $\mathrm{K}$ úmido e, para um dado solo e local, os valores mensais utilizados para compor o valor médio anual eram escolhidos em função dos seguintes critérios: K úmido se a média mensal de chuva excedesse a evaporação do tanque classe $A$, ou se a chuva mensal em um dado mês excedesse $1 / 12$ ou $8,5 \%$ do total anual da chuva, ou ainda se a chuva ocorrida durante o mês precedente excedesse $17 \%$ do valor anual. Para todos os outros meses a contribuiça para o $\mathrm{K}$ médio anual era $\mathrm{K}$ seco.

Investigando a variação que ocorre na erodibilidade do solo entre diferentes anos, ALBERTS et al. (1987) concluiram que determinaçóes da erodibilidade com apenas um ano de simulação de chuvas precisam ser cuidadosamente interpretadas e que, para explicar tais variaços, maior 
ênfase deve ser dada ao estudo dos atributos do solo que variam com o tempo, tais como densidade, resistencia e estabilidade e tamanho de agregados. Lembram que quando o fator erodibilidade do solo é determinado a partir de dados de perdas de solo de vários anos, em parcelas padrão, mudanças temporais no solo e sua resistencia ao selamento e desagregação tornam-se parte da variação inexplicada, que geralmente se supõe, em grande parte, ser devida d̀ umidade antecedente do solo relacionada a ocasião de ocorrencia dos principais eventos de escorrimento superficial.

Para compensar parte da erodibilidade que estava sendo considerada dentro do fator $C$, e assim poder subdividir com mais precisão este último em subfatores, MUTCHLER et al. (1982) aplicaram ao fator $\mathrm{K}$ convencional um coeficiente, Kc, atribuido a variações da erodibilidade devido a umidade antecedente do solo. Observaram que podem ser encontradas grandes variações nos valores de $K$ obtidos para as estaçós de um ano com conteúdo variável de água no solo e propuseram que a EUPS deveria ser revista para permitir estimativas de perdas de solo em fases de culturas, assumindo a forma:

$$
A=R(\mathrm{Rc}) \cdot \mathrm{K}(\mathrm{Kc}) \cdot \mathrm{L} \cdot \mathrm{S} \cdot \mathrm{Cs} \cdot \mathrm{P}
$$

onde: Rc ajustaria o fator $R$ de erosividade da chuva-enxurrada, Cs seria um grupo de subfatores de uso e manejo do solo $\left(C_{1} \cdot C_{2} \cdot C_{3} \cdot C_{4} \cdot C_{5}\right)$ e os demais termos conforme definidos anteriormente.

De acordo com Young et al. (1985), a erodibilidade do solo é uma propriedade dinamica que varia com a umidade do 
solo, temperatura, forma de preparo do solo e ainda fatores biológicos e quimicos. Sugerem que para a modelagem da natureza dinâmica da erodibilidade do solo poderia ser usada uma aproximação com subfatores, semelhante à que é feita com - fator C da EUPS.

MUTCHLER \& CARTER (1983) mostraram, a partir de parcelas sob chuva natural, que a erodibilidade do solo varia periodicamente durante o ano, podendo ser descrita por uma função cosseno. Sugeriram que a erodibilidade para um determinado mês poderia ser predita usando-se a variação dos dados de temperatura do ar para o local considerado, que também acompanha uma cossenóide, e valores de K médio anual dos diversos solos.

IMESON \& VIS (1984) estimaram a erodibilidade a partir de experimentos de simulação da desagregação pelo impacto da gota de chuva em laboratório utilizando amostras de solo indeformadas, de determinaçoses da estabilidade de agregados e determinações de campo do salpicamento. As amostras foram coletadas a intervalos mensais em áreas de florestas, pastagens e lavouras. Todos os locais exibiram variações estacionais significativas na erodibilidade.

Parcelas padrão foram monitoradas de setembro de 1983 a agosto de 1985 para avaliar a variaça estacional da erodibilidade de quatro solos em Quebec, no Canadá. Através de uma modificação no termo de erosividade da chuvaenxurada, a erodibilidade foi calculada para cada evento individual de escorrimento superficial. Foram requeridas 
grandes diferenças entre as médias para atingir significância estatística devido à grande variabilidade nos dados (KIRBY \& MEHUYS, 1987 ).

COOTE et al. (1988) chegaram a resultados que proporcionaram mais um entendimento a respeito do importante e complexo problema de predição da erodibilidade do solo. Mudanças temporais na resistência do solo ao cisalhamento e na estabilidade dos agregados foram primariamente, mas não exclusivamente, relacionadas a mudancas em seu conteúdo de água. O aquecimento do solo pareceu afetar o restabelecimento da resistência à erosão em solos tornados erodiveis pelo congelamento, degelo e saturação.

Dados de parcelas de campo sob chuva natural, de laboratório com simulador de chuvas e uma equação preditora do fator $K$ da EUPS foram usados para avaliar a variaça estacional da erodibilidade de solos do sudoeste de ontario, no Canada. A magnitude desta variaça, achada significativa, foi diferente em função das diversas classes texturais representadas e do metodo utilizado (WALL et al, , 1988).

YOUNG et a 1. (1990) observam que, dentre os fatores envolvidos, uma parte significativa da incerteza em relação aos valores obtidos para o $\mathrm{k}$ medio anual resulta de variaçoes na umidade antecedente e nas condições da superfície do solo existentes por ocasião dos eventos e também de variaçós estacionais nas propriedades do solo determinantes da erosa. Acrescentam que como há uma tendencia de consistencia estacional nos valores destas condiços e propriedades, 
acredita-se que valores estacionais de $\mathrm{K}$ poderiam reduzir erros nas estimativas de perdas de solo.

Utilizando dados de uma provincia canadense e de sete estados americanos RENARD et al.' derivaram relaçóes capazes de considerar a variação estacional da erodibilidade do solo, ponderando estimativas instantâneas de $\mathrm{K}$ em relaçäo a porcentagem do $R$ anual para intervalos de 15 dias.

MEYER \& HARMON (1992) avaliaram as variaçós temporais nas taxas de erosão e nas distribuições do tamanho dos sedimentos na medida em que eram influenciadas pelo crescimento da cultura, condiçôes do solo, chuva continuada e uso anterior da terra. Seus resultados indicaram que a erodibilidade do solo pode mudar apreciavelmente durante o ano e que isto deve ser considerado na avaliação e aplicação dos valores representativos correspondentes em modelagem.

Estudando a erosividade da chuva-enxurrada, sua distribuição e correlação com as perdas de solo em Campinas e Mococa-SP, BERTONI et a1. (1975), LOMBARDI NETO (1977),

1 RENARD, K.G.; FOSTER, G.R.; WEESIES, G.A.; MCCOOL, D.K., coord. (USDA-ARS, Tucson, Arizona; University of Minnesota, St. Paul, Minnesota; USDA-SCS, NSERL, Purdue University, West Lafayette, Indiana; USDA-ARS, Washington state University, Pullman, washington). predicting soil erosion by water; a guide to conservation planning with the Revised Universal soil Loss Equation - RUSLE. (Em elaboração) 
LOMBARDI NETO (1979), CARVALHO (1987), CARVALHO et a 1. (1989) e CARVALHO (1992) obtiveram as primeiras aproximaçōes do fator erodibilidade (K médio anual) para os solos envolvidos no presente trabalho. 
12 .

\section{MATERTAL E METODOS}

\subsection{Material}

Foram utilizados dados de perdas de solo e enxurrada, referentes ao periodo de julho de 1979 a junho de 1985, obtidos pela Seção de Conservação do Solo no Centro Experimental de Campinas e na Estação Experimental de Mococa, pertencentes ao Instituto Agronômico do Estado de São Paulo (IAC), Brasil (Figura 1). Os indices EI 30 de erosividade da chuva-enxurada para cada evento foram obtidos a partir dos trabalhos de CARVALHO (1987) e CARVALHo (1992) realizados em conjunto com a mesma Seção.

A Seção de Climatologia Agrícola do referido Instituto forneceu dados climatológicos adicionais correspondentes ao periodo considerado e tambem as Normais Climatológicas de 1961 a 1990.

o Centro Experimental de Campinas está localizado de acordo com as coordenadas geograficas $22^{\circ} 54^{\prime} \mathrm{s}$ e $47^{\circ} 05^{\prime} \mathrm{W}$. Possui uma área total de 767 ha e altitude média de 674 metros. A precipitação média anual é de $1.381 \mathrm{~mm}$, sendo a média antal de temperatura $20,7^{\circ} \mathrm{C}$. O tipo climático é Cwa, de acordo com o critério de koeppen, definido como mesotérmicoúmido com veróes quentes. o solo onde a parcela 
de campo ficou instalada é um Latossolo Roxo distrofico, A moderado, textura argilosa (Typic Haplortox).

A Estação Experimental de Mococa possui as coordenadas $21^{\circ} 28^{\prime} \mathrm{s}$ e $47^{\circ} 01^{\prime} \mathrm{w}$, área total de 474 ha e altitude média de 665 metros. A precipitação média anual é de $1.500 \mathrm{~mm}$, sendo a média anual de temperatura $21,8^{\circ} \mathrm{C}$. $\mathrm{O}$ tipo climatico é Aw, tropical úmido com estaça chuvosa no verão e seca no inverno, e o solo da parcela de campo um Podzólico Vermelho-Amarelo eutrofico, Tb, A chernozemico, textura argilosa/muito argilosa (Oxic Argiudoll).

Na Tabela 1 encontram-se atributos do horizonte superficial dos solos estudados, conforme DENARDIN (1990). As características das parcelas de campo e dos sistemas coletores de solo e enxurrada seguem as especificações de BERTONI (1949). As referidas parcelas tem uma área de $100 \mathrm{~m}^{2}$, com $25 \mathrm{~m}$ de comprimento no sentido do declive por $4 \mathrm{~m}$ de largura, e declive uniforme de $9,9 \%$ e $9,4 \%$ para Campinas e Mococa respectivamente. O sistema coletor de solo e enxurrada, adaptado a jusante da soleira das parcelas, foi construido de alvenaria, inclusive a soleira e a parede divisória. Possui dois tanques ligados por um divisor de janelas do tipo geib para fracão de $1 / 7$. o primeiro, acoplado à soleira, destina-se à decantaça do solo arrastado pela enxurrada, enquanto que o segundo, acoplado ao primeiro, capta $1 / 7$ da enxurrada. 


\subsection{Métodos}

As parcelas de campo foram mantidas descobertas, sob chuva natural, sendo preparadas e cultivadas com enxada e enxada, seguindo as mesmas recomendações feitas à parcela unitária de BERTONI \& LOMBARDI NETO (1990). Esta parcela unitaria possui $25 \mathrm{~m}$ de comprimento e uma declividade uniforme de $9 \%$, em alqueive, preparada no sentido do declive. Alqueive, neste caso, significa um terreno que foi preparado e deixado livre de vegetação por um mínimo de 2 anos, ou até que os residuos da cultura anterior estivessem decompostos. Durante o periodo de determinação de perdas de solo, em cada primavera, a parcela é preparada e deixada em condições convencionais, como para o plantio de milho, sendo capinada quando necessário para prevenir o crescimento de plantas invasoras ou formação de crostas superficiais.

As determinações de perdas de solo e enxurrada são feitas diariamente toda vez que ocorre uma chuva que proporciona perda de solo e/ou perda de água de enxurrada, efetuando-se o esvaziamento e a 1 impeza dos tanques coletores e, posteriomente, avaliando-se as quantidades correspondentes.

Para as perdas de solo foi procedida uma correção em relação ao declive de $9 \%$ da parcela unitária utilizando-se a fórmula LS $=0,00984 \cdot \mathrm{C}^{0,63} \cdot \mathrm{D}^{1,18}$ de BERTONI \& LOMBARDI NETO (1990), onde L e $S$ são os fatores topográficos da EUPS, C o comprimento de rampa em metros e $D$ o grau de declive em 
porcentagem.

A erodibilidade do solo foi estimada de duas maneiras distintas. A primeira correlaciona as características da chuva com a perda de solo correspondente através da regressão 1 inear simples. Na equaço $y=a+b x$, onde y representa a perda de solo e $x$ o indice de erosividade da chuva-enxurada $\left(\mathrm{EI}_{30}\right)$, o fator $\mathrm{K}$ é representado pelo coeficiente angular da reta resultante, b, quando os dados são obtidos nas condições de parcela unitária. Esta abordagem facilita o estabelecimento de limites de confiança para os valores de $\mathrm{K}$ obtidos a partir de dados de curto prazo (WISCHMEIER, 1972). O procedimento acima descrito foi adotado para estimar valores de $\mathrm{K}$ médios anuais, estacionais e mensais $(\mathrm{Ka}, \mathrm{Ke} \mathrm{e} \mathrm{Km})$, verificando-se a significância das regressões com o teste $F$ e se o coeficiente a diferiu estatisticamente de zero através do teste $t$.

A segunda maneira de obter o índice de erodibilidade considerou que, da mesma forma que $K=A / R$ em parcelas unitárias, $\mathrm{K}=\Sigma A / \Sigma E I_{30}$, inclusive para partes do ano (FOSTER et a 1., 1981; MUTCHLER \& CARTER, 1983). Is to tamberm foi feito para obter estimativas de $K$ medios anuais, estacionais e mensais.

Considerou-se estação do ano como um período no qual as condições hidrológicas de uma área tais como clima, características do solo, cobertura vegetal e uso da terra devem ser assumidas como permanecendo as mesmas, e ocorrendo todo ano durante a mesma época (BORAH \& ASHRAF, 1990). Para 
tal distinção utilizaram-se as Normais climatológicas de precipitação pluvial e de temperatura média do ar (Tabela 2), definindo duas estações básicas: uma quente e úmida de outubro a março e outra fria e seca de abril a setembro (Figuras 2 e 3). Segundo LOMBARDI NETO (1977) e CARVALHO (1987), considerando os períodos de 1954 a 1975 e de 1966 a 1985, a distribuição média do f́ndice $E_{30}$ de outubro a março é de $90,9 \%$ e $88,5 \%$, contra $9,1 \%$ e $11,5 \%$ de abril a setembro, para Campinas e Mococa respectivamente.

Todos os cálculos consideraram o período inteiro de observação em conjunto, buscando valores representativos para os seis anos abrangidos pelo estudo.

Seguindo a tendência de MUTCHLER et al. (1982), MUTCHLER \& CARTER (1983), MUTCHLER e MURPHREE (1985) e WALL et al. (1988), foram calculados indices temporais Kc para o fator K da EUPS (Kce $\mathrm{e}$ Kcm) dividindo-se os valores dos $K$ médios estacionais e mensais pelo $\mathrm{K}$ médio anual, o que permite ajustar o modelo preditor para períodos menores que um ano.

Os dados foram processados em microcomputadores do tipo PC, utilizando-se programas estatisticos e planilhas eletrônicas de uso generalizado. Também foram utilizadas funções estatísticas de calculadoras eletrônicas. o estabelecimento de intervalos de confiança para os valores de $\mathrm{K}$ e os testes estatisticos aplicados seguiram a orientaça de SPIEGEL (1968) e HOFFMANN \& VIEIRA (1977). 
17.

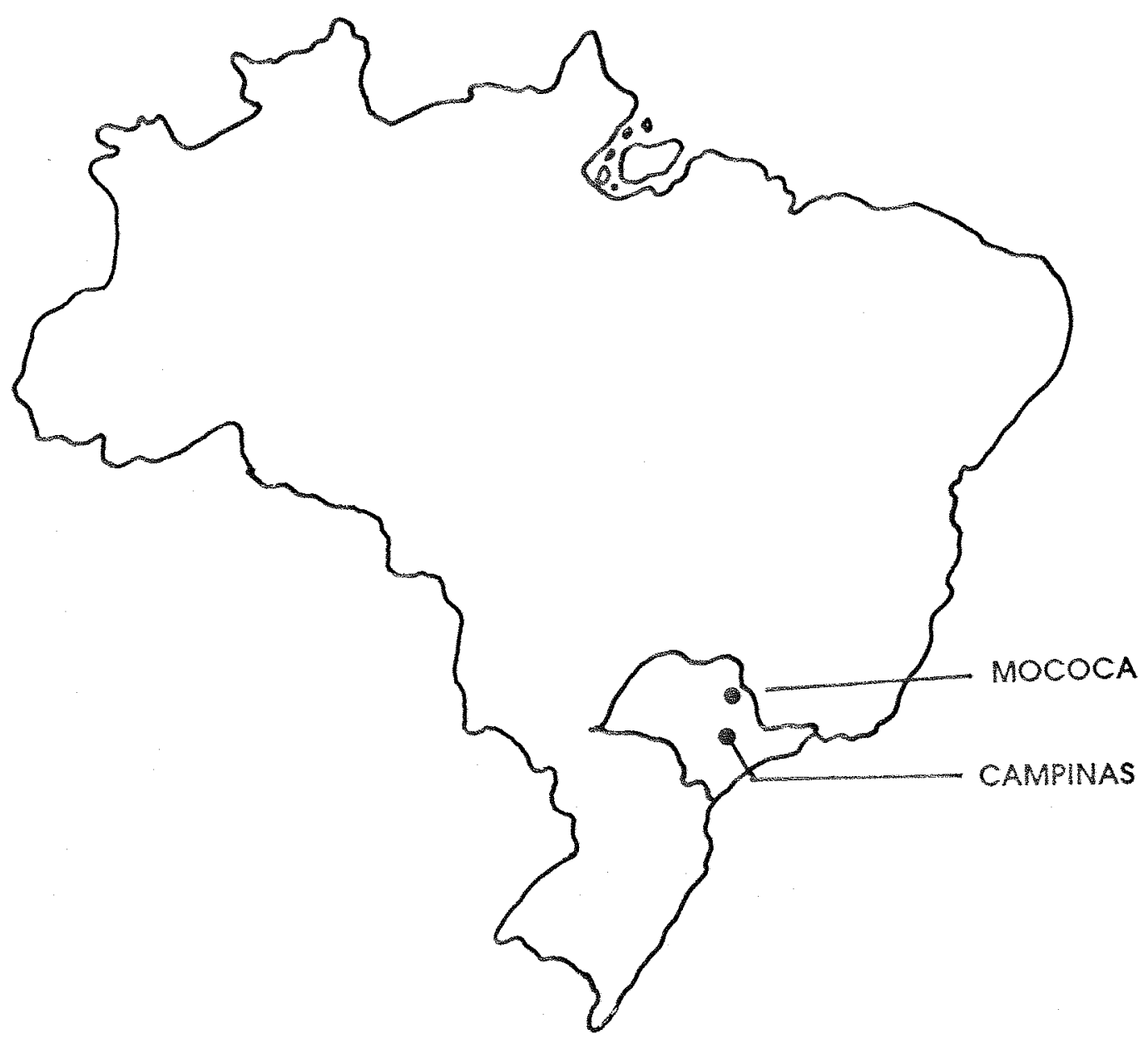

Figura 1. Mapa mostrando a localização dos municípios de Campinas e Mococa. 
Tabela 1. Atributos do horizonte superficial $(0-20 \mathrm{~cm})$ dos solos estudados

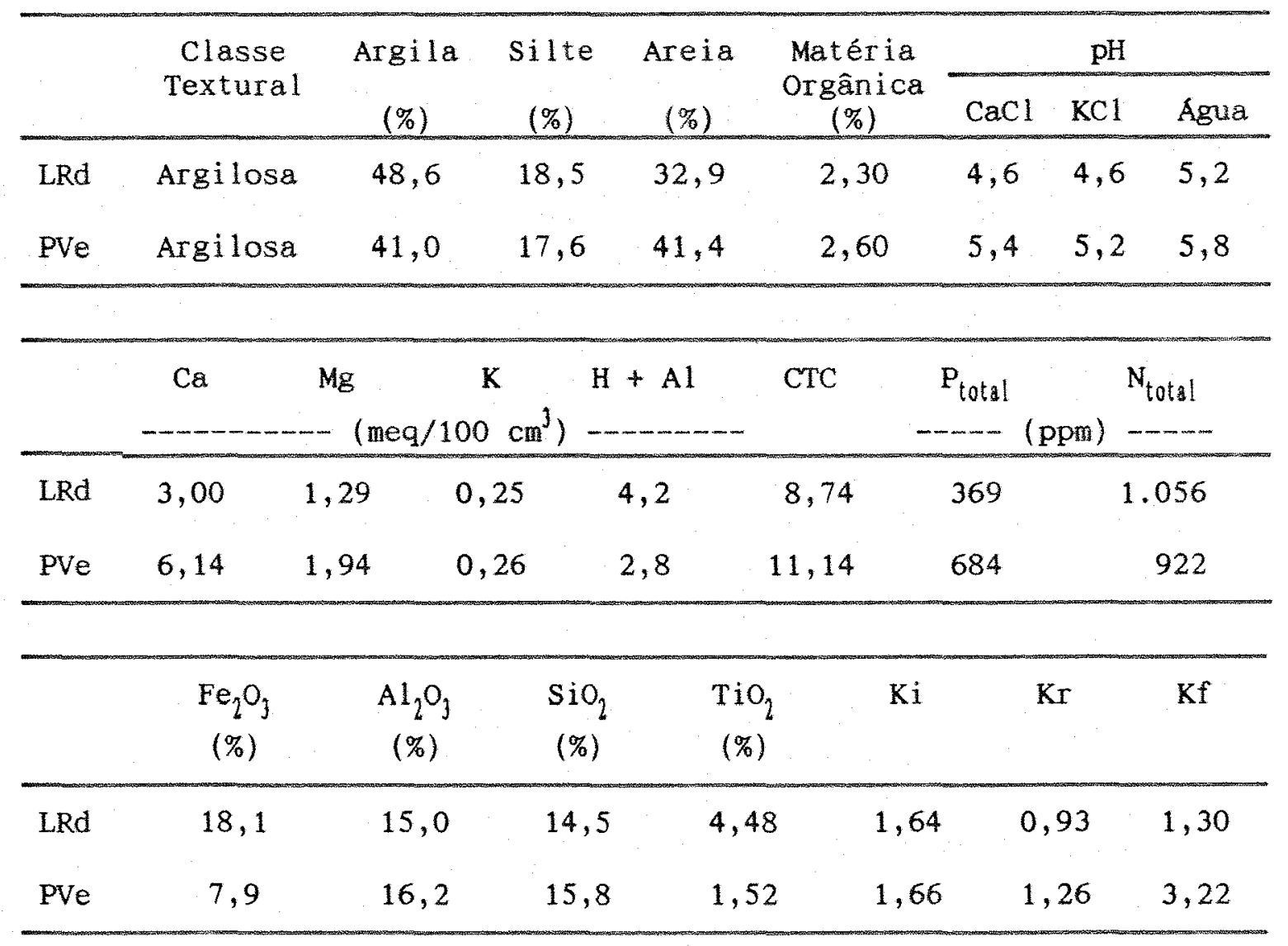

Fonte: DENARDIN (1990). 
Tabela 2. Normais Climatológicas de precipitaço pluvial e temperatura média do ar para Campinas e Mococa referentes ao período de 1961 a 1990

\begin{tabular}{|c|c|c|c|c|}
\hline \multirow[b]{2}{*}{ Mês } & \multicolumn{2}{|c|}{ CAMPINAS } & \multicolumn{2}{|c|}{ MOCOCA } \\
\hline & $\begin{array}{c}\text { Precipitação } \\
(\mathrm{mm})\end{array}$ & $\begin{array}{c}\text { Temperatura } \\
\left({ }^{\circ} \mathrm{C}\right)\end{array}$ & $\begin{array}{c}\text { Precipitação } \\
(\mathrm{mm})\end{array}$ & $\begin{array}{c}\text { Temperatura } \\
\left({ }^{\circ} \mathrm{C}\right)\end{array}$ \\
\hline Jan & 240,2 & 23,0 & 247,0 & 23,5 \\
\hline $\mathrm{Fev}$ & 190,9 & 23,3 & 203,2 & 23,6 \\
\hline Mar & 147,3 & 22,9 & 159,0 & 23,3 \\
\hline $\mathrm{Abr}$ & 71,0 & 21,0 & 74,4 & 21,8 \\
\hline Mai & 65,1 & 18,7 & 64,2 & 19,6 \\
\hline Jun & 48,7 & 17,3 & 31,1 & 18,5 \\
\hline Jul & 36,8 & 17,3 & 25,1 & 18,5 \\
\hline Ago & 37,4 & 18,9 & 29,6 & 20,7 \\
\hline Set & 65,6 & 20,3 & 70,2 & 22,2 \\
\hline Out & 123,6 & 21,3 & 131,8 & 22,9 \\
\hline Nov & 137,5 & 22,1 & 185,3 & 23,2 \\
\hline Dez & 217,1 & 22,5 & 279,3 & 23,2 \\
\hline ANO & $1.381,2$ & 20,7 & $1.500,2$ & 21,8 \\
\hline
\end{tabular}

Fonte: SEÇÃO DE CLIMATOLOGIA AGRICOLA - IAC. 


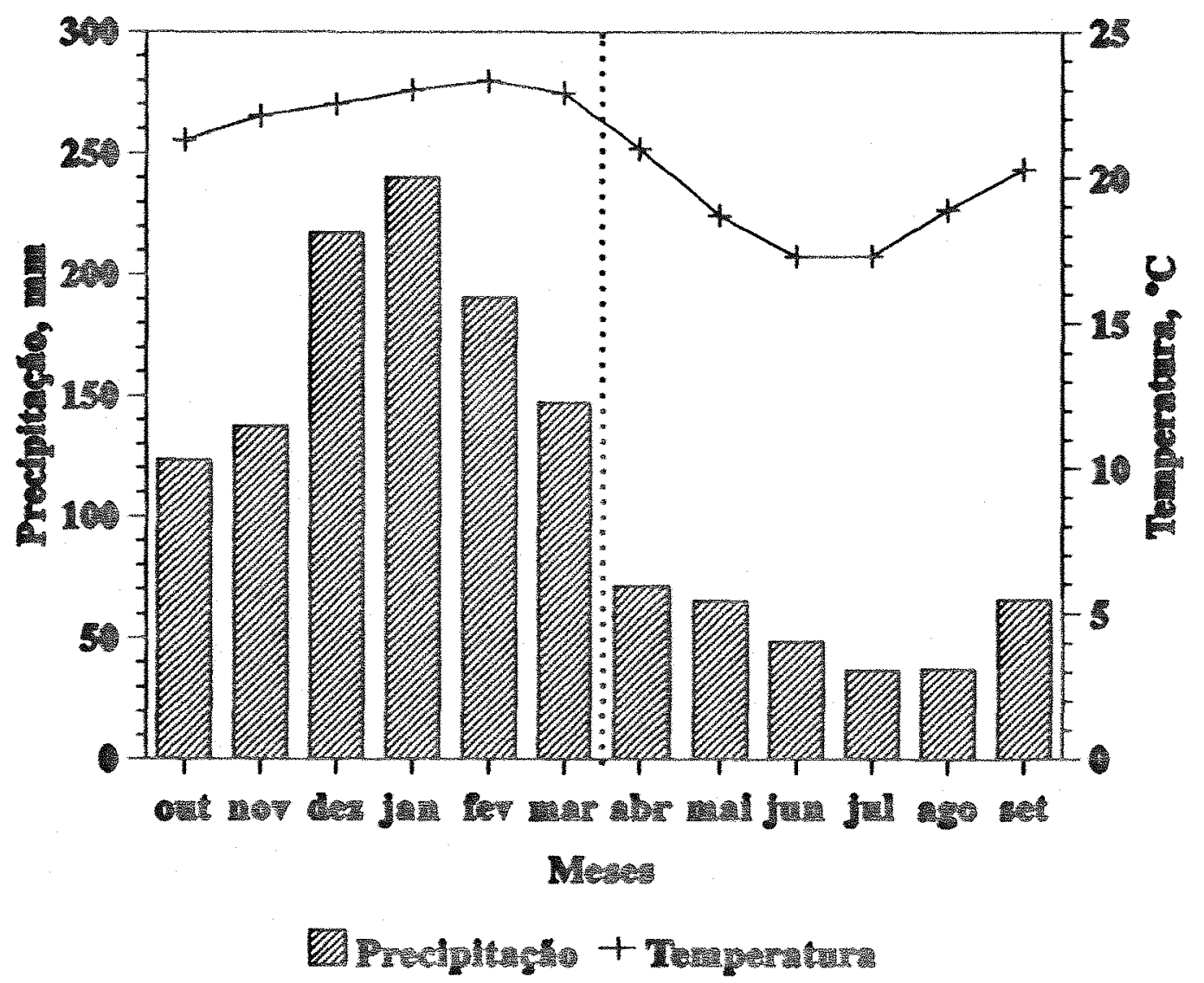

Figura 2. Estações do ano baseadas nas Normais Climatológicas de precipitação pluvial e temperaturamédia do ar (1961-1990) - Campinas (SP). 


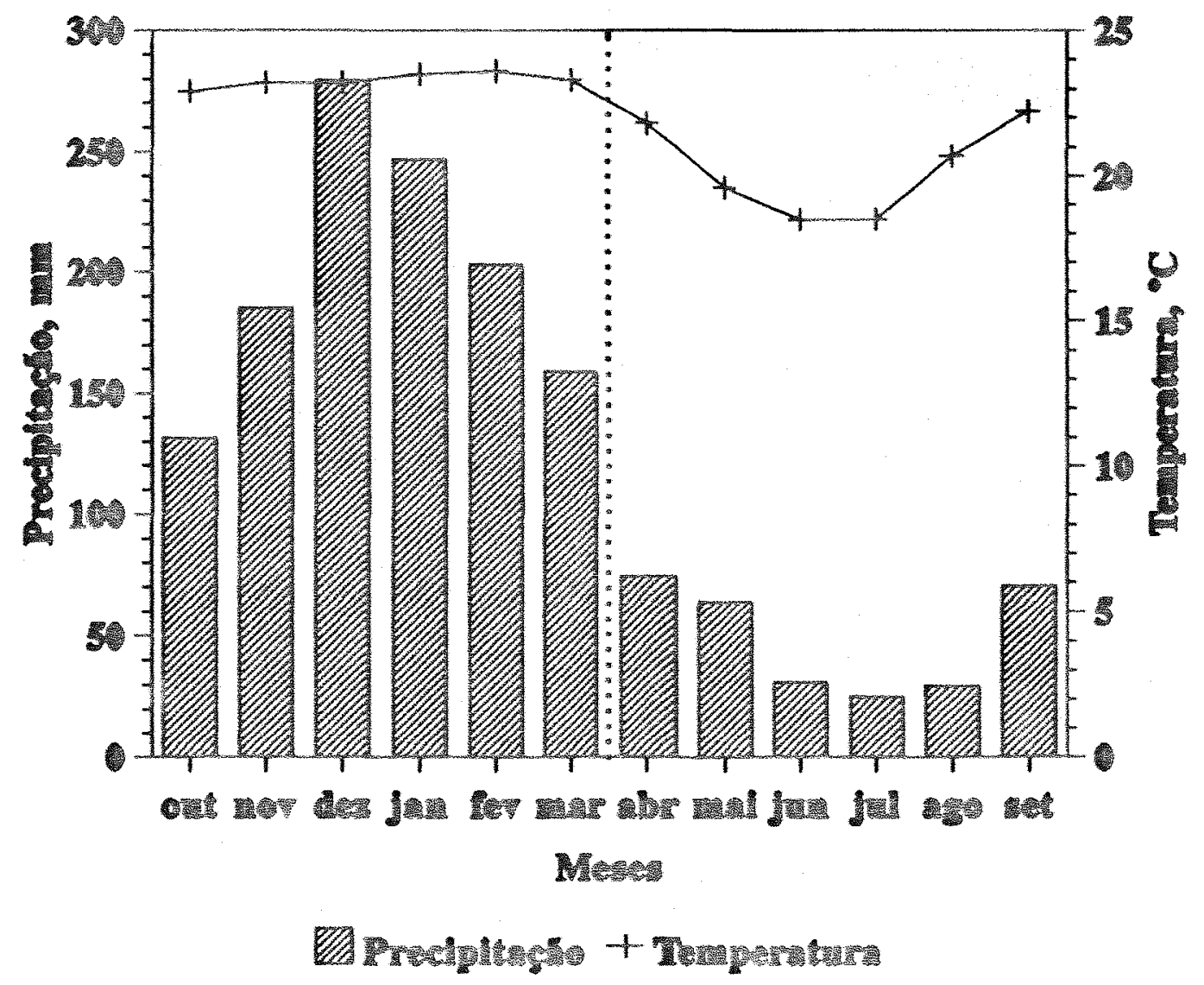

Figura 3. Estações do ano baseadas nas Normais Climato$16 g$ icas de precipitação pluvial e temperatura média do ar (1961-1990) - Mococa (SP). 


\section{RESULTADOS}

A partir dos dois métodos utilizados para estimar os valores do fator $K$ da EUPS, que representa a erodibilidade do solo, chegou-se aos resultados que seguem.

Nas Tabelas 3 e 4 são apresentados os produtos das regressões lineares simples, através das quais se obteve, para os dados experimentais de perdas de solo e de erosividade da chuva-enxurrada, coeficientes de equaçóes de retas $(y=a+b x)$ acompanhados dos resultados dos testes de significância aplicados. Constam também nestas tabelas os intervalos de confiança ao nível de $5 \%$ de probabilidade para os valores de $\mathrm{K}$ médios anual, estacionais e mensais e os índices Kc para cada estação e mês, de acordo com este método.

As médias anuais, estacionais e mensais, e, destas últimas os respectivos desvios padrão, da precipitação pluvial total, do indice $\mathrm{EI}_{30} \mathrm{e}$ das perdas de solo, para período considerado no presente trabalho, estão discriminados nas Tabelas 5 e 6 . Aí se encontram as estimativas dos valores de $\mathrm{K}$ médios anual, estacionais e mensais obtidos pela divisão $\Sigma \mathrm{A} / \Sigma \mathrm{EI}_{30} \mathrm{e}$ os índices $\mathrm{Kc}$ correspondentes.

Buscando avaliar tendências temporais e atender ao 
objetivo de comparar os resultados para os solos estudados, e pelos dois métodos utilizados, foram plotados em gráficos, representados nas Figuras 4 e 5 , os valores dos índices Kc mensais anteriormente apresentados. Os citados gráficos permitem visualizar, simultaneamente para os dois solos, a variação da erodibilidade durante o ano tomando-se por base a oscilação dos $\mathrm{K}$ médios mensais em torno do valor central do $\mathrm{K}$ médio anual. 


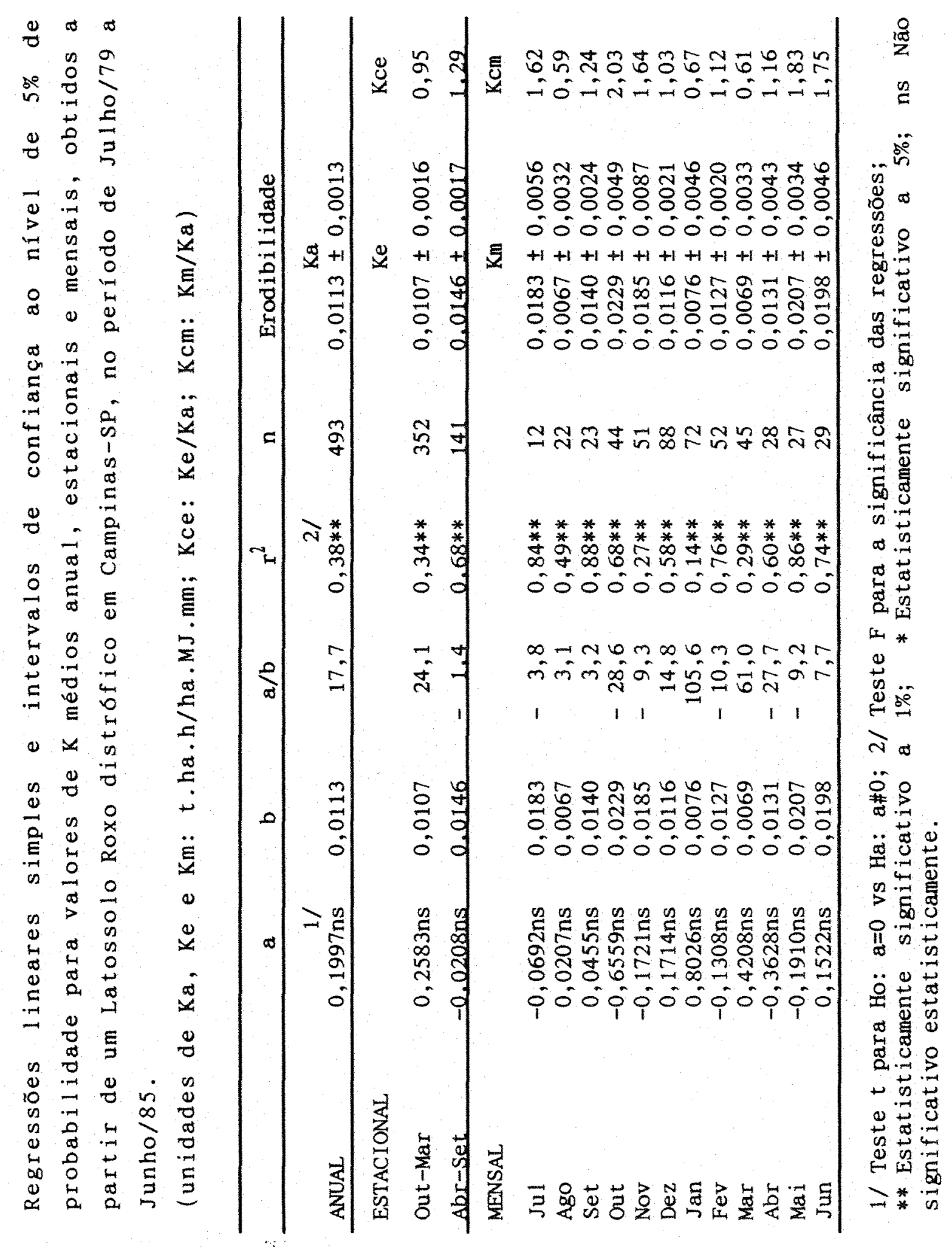

24. 


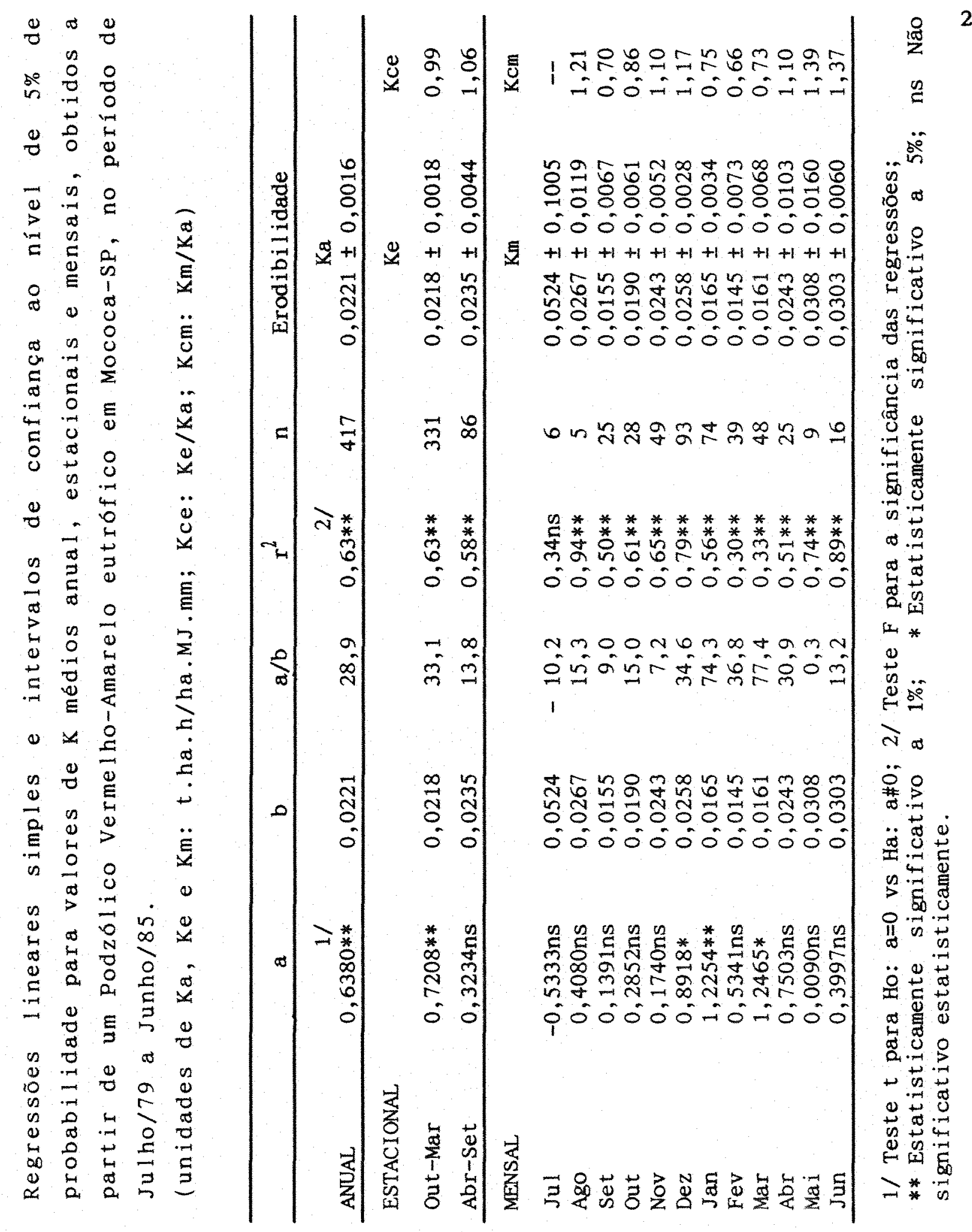




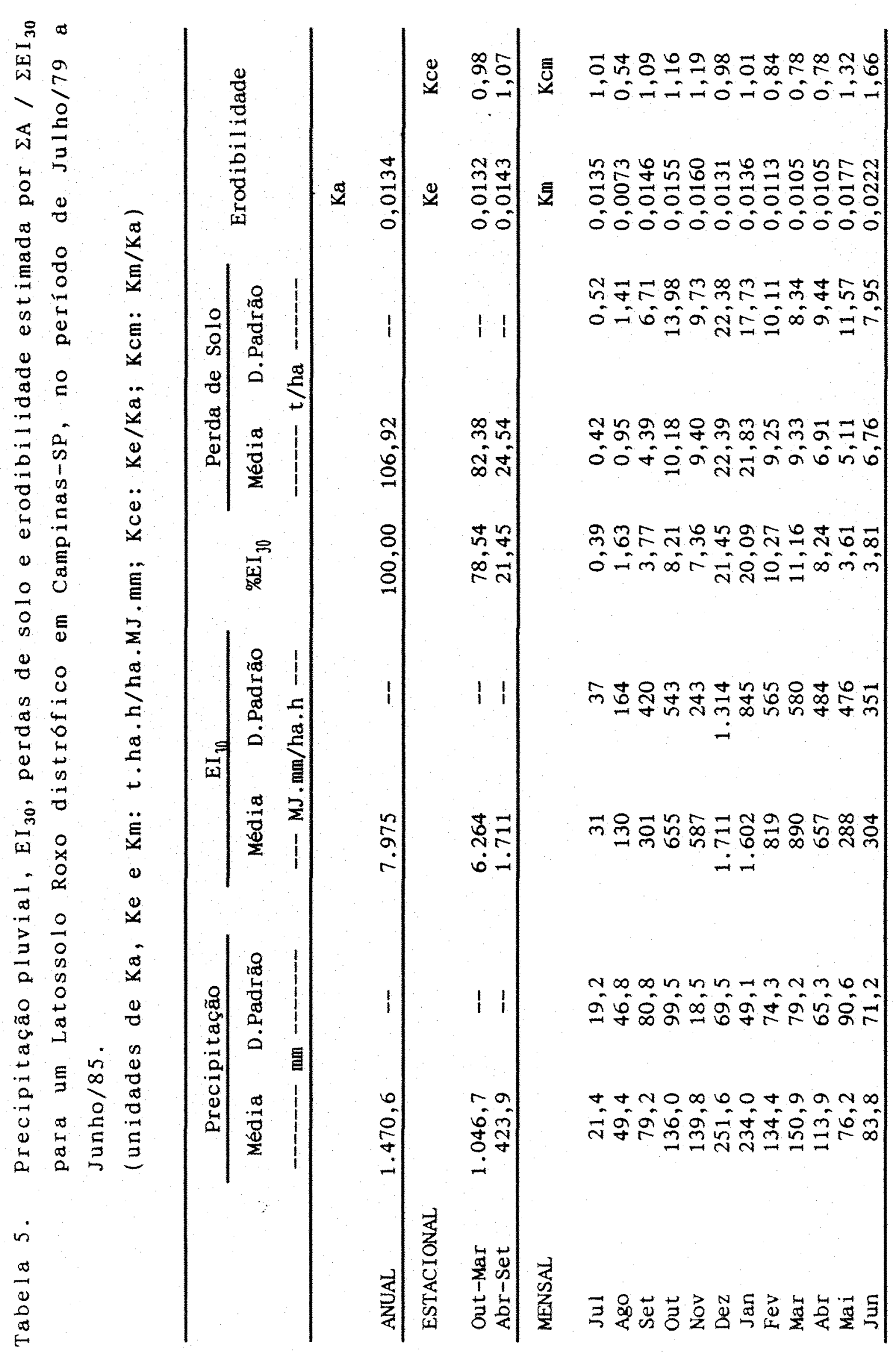


27.

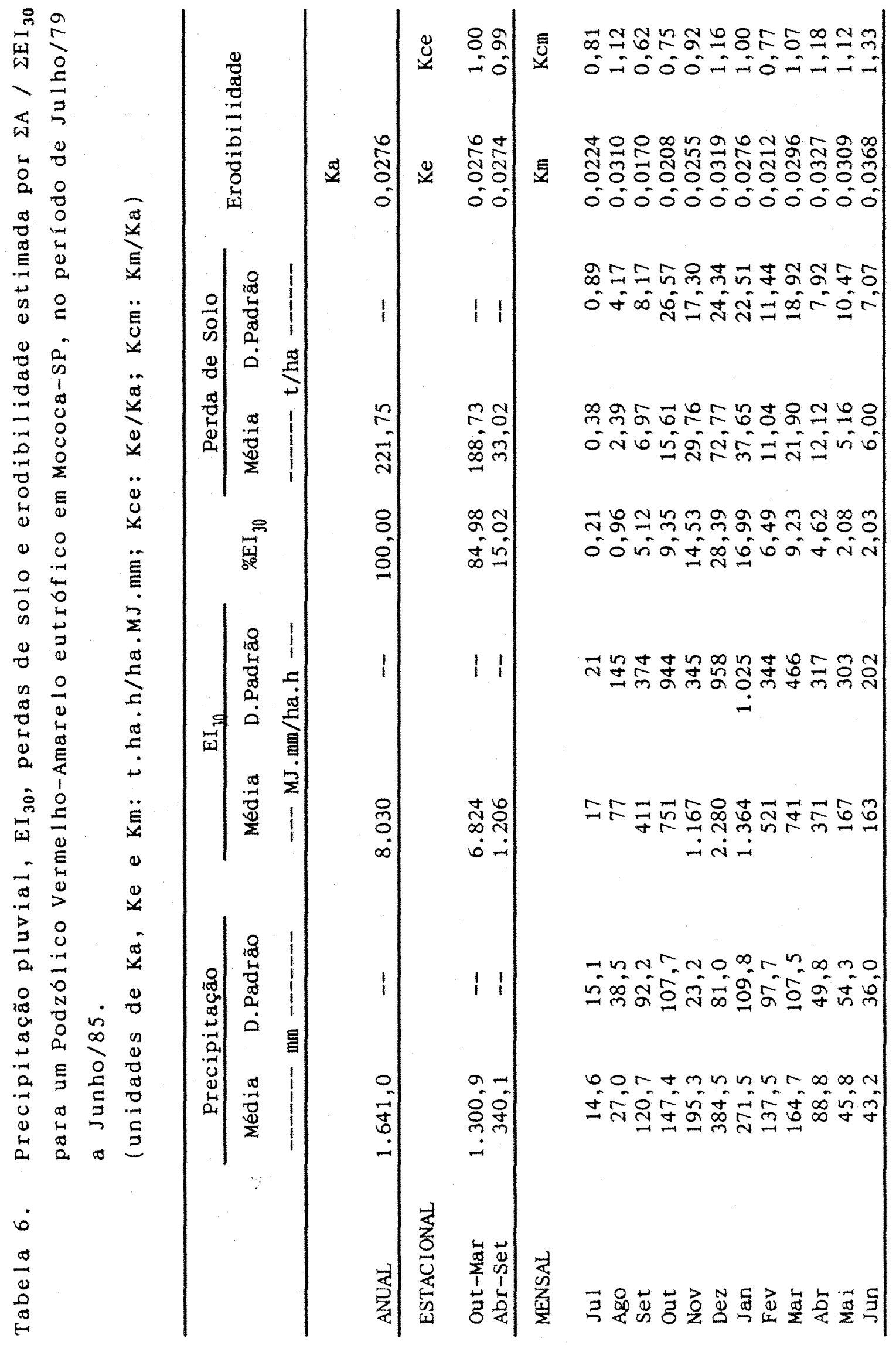


28 .

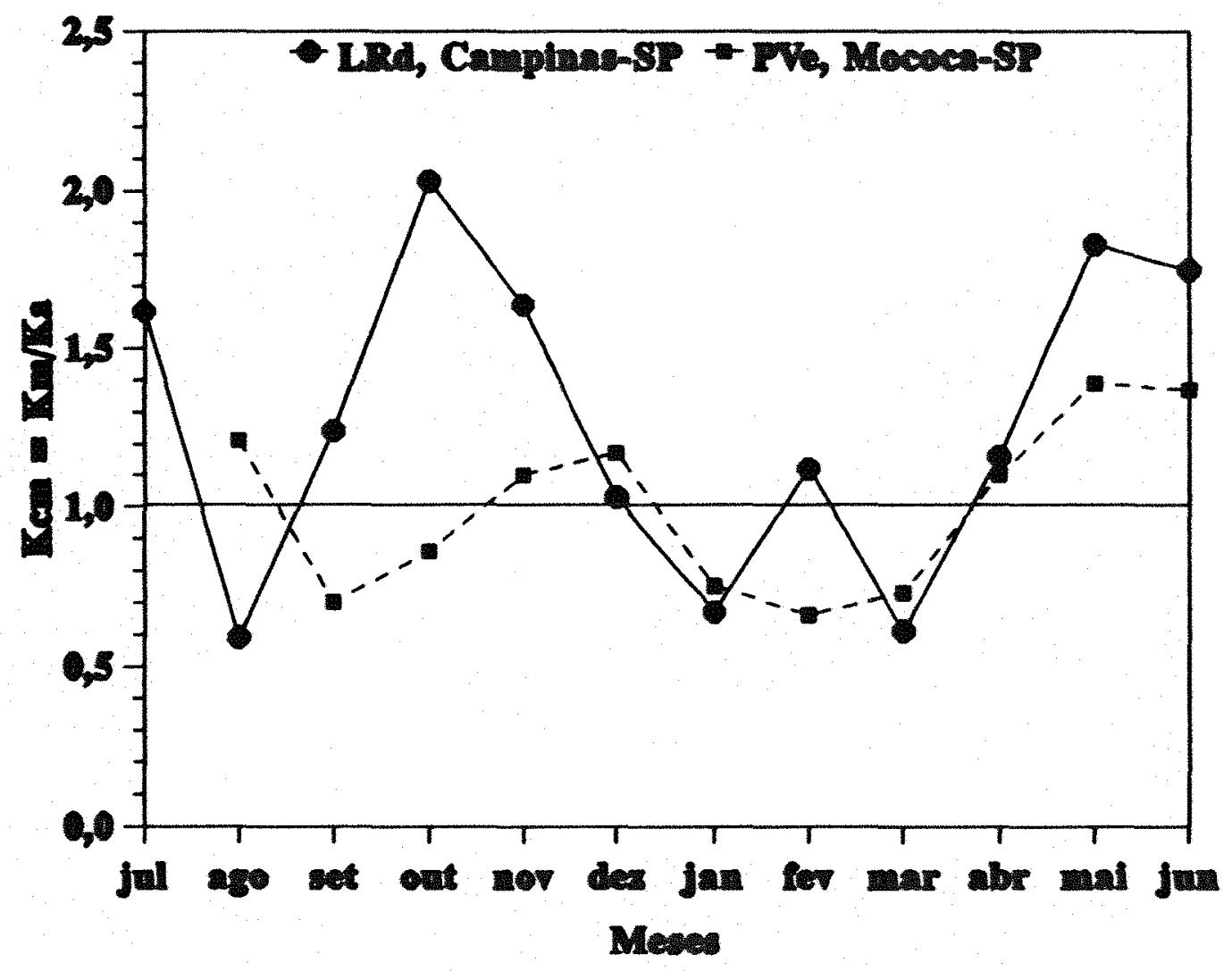

Figura 4. Variação da erodibilidade do solo durante o ano, est imada por regressão linear simples. 
29.

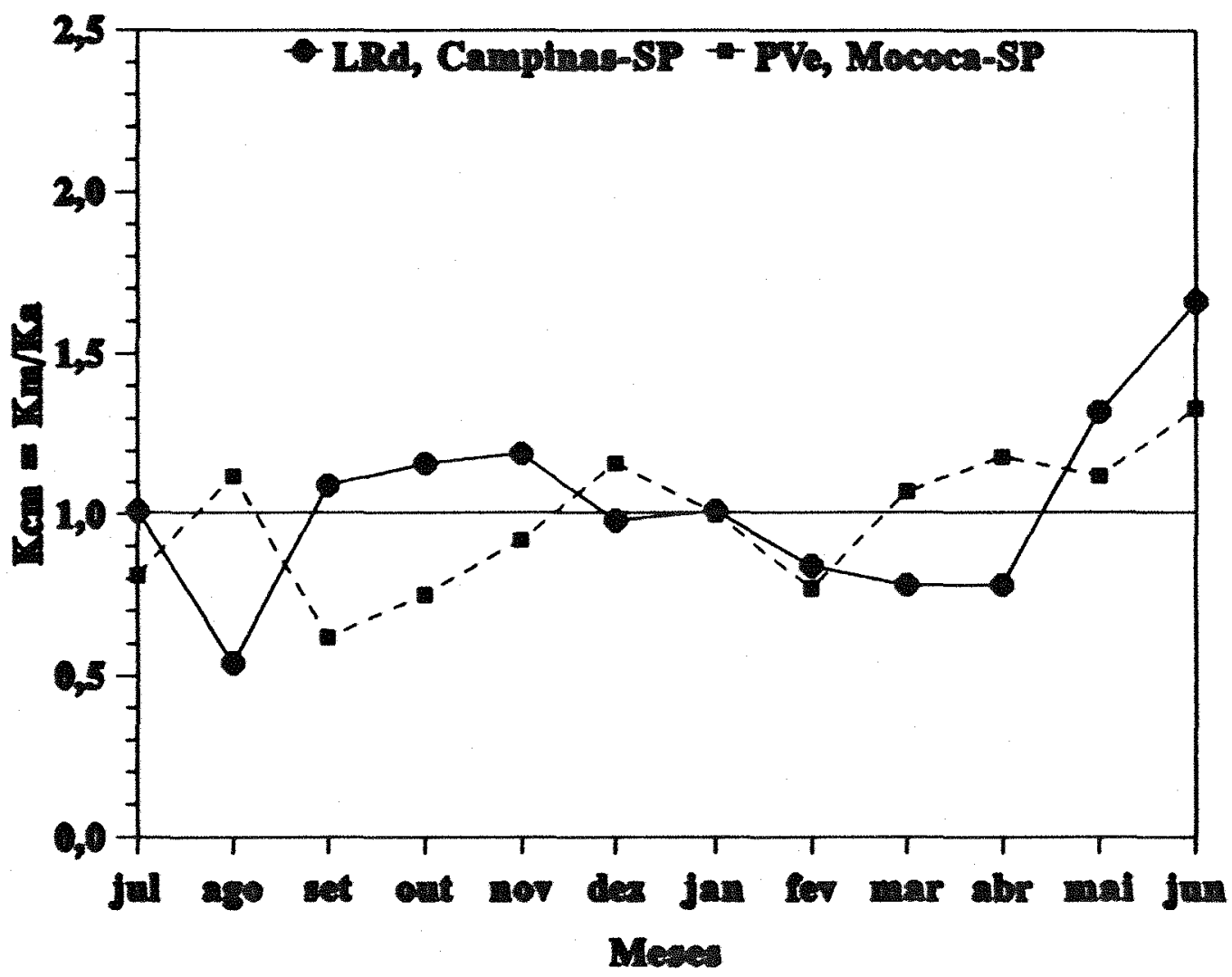

Figura 5. Variação da erodibilidade do solo durante o ano, est imada por $\Sigma A / \Sigma E I_{30}$. 


\section{DISCUSSÃO}

Considerando os resultados apresentados nas Tabelas 3 e 4 podemos observar, em primeiro lugar, que os coeficientes lineares a, que representam as intersecções das retas obtidas com o eixo y das ordenadas, tem magnitude e sinais variáveis. Isto está de acordo com WISCHMEIER \& MANNERING (1969) que apontam diferenças na umidade antecedente e nas condições de superfície, que se alteram no decorrer do tempo, como causas desta variação. Observa-se também, contrariando estes mesmos autores, que mesmo sob chuva natural, os valores negativos das interseções com o eixo y não são desprezíveis, podendo chegar em termos absolutos a 28,6 vezes o valor do coeficiente angular da reta, o que ocorreu com os dados do mês de outubro para o Latossolo Roxo distrófico de Campinas. A relação a/b extrema para interseções positivas foi 105,6 , obtida com dados de janeiro, também para o LRd de Campinas.

Por outro lado, conforme relatado por MUTCHLER et al. (1988), algumas restrições feitas no cálculo do índice EI $_{30}$ de erosividade da chuva-enxurrada são uma tentativa de aproximar de zero o coeficiente linear a para atender a proporcionalidade de $A, R$ e $K$. Para qualquer outra 
localidade ou situação que esteja fora da base de dados de origem da EUPS deve-se verificar e, se necessário, adaptar estes critérios. Segundo RöMKENS (1985), diferenças nas áreas fisiográficas, no tipo de solo e sua manipulação e valores estacionais do fator $K$ são requerentes de tais modificações.

De fato, verificando se o coeficiente linear a diferia estatisticamente de zero, encontraram-se diferenças significativas em Mococa para as regressões anual, estacional de outubro a março e para as referentes aos meses de dezembro, janeiro e março. Nestes casos o modelo linear para a estimativa da erodibilidade não está bem ajustado. E em geral, notamos que a relação a/b não nos oferece uma informação consistente com a significância estatistica do coeficiente a.

MUTCHLER et al. (1988) observam que a erosividade e a erodibilidade devem ser avaliadas conjuntamente porque elas são essencialmente a causa e ofeito da erosão. Conforme LAFLEN (1982), os valores de $K$ não são independentes dos valores de $R$ e, de acordo com McISAAC \& MITCHELL (1992), a parcela da variação da erodibilidade devida a variações em propriedades do solo ou devida a características da chuva ainda é desconhecida.

Segundo SPIEGEL (1968), os coeficientes de determinação $r^{2}$ são quocientes da variação explicada para a variação total em relação às retas resultantes. Se a variação explicada for nula, esse quociente será igual a 
zero. Se a variação total for toda explicada, o quociente será igual a 1. Nota-se nas referidas tabelas que, exceto para o mês de julho em Mococa, as regressões foram altamente significativas, porém, valores mais baixos de $r^{2}$ indicam que a dispersão de pontos obtida experimentalmente se comporta, em grande parte, de maneira casual ou imprevisível.

Os valores estimados para o fator $\mathrm{K}$ da USLE aparecem acompanhados de intervalos de confiança. GRAYBILL (1961) pondera que em estudos científicos geralmente não é essencial encontrar o valor exato de um parâmetro sob investigação. E desejável, entretanto, ter alguma confiança de que o valor obtido está dentro de certos 1 imites preestabelecidos.

Se uma amostra é representativa de uma população, conclusões importantes sobre a população podem ser inferidas de sua análise. No presente trabalho considerou-se como amostras as observações realizadas no período dos 6 anos estudados e como populações a conjunto de observações de que se disporia numa série de anos mais longa. Como o nível de probabilidade escolhido foi de $5 \%$, isto significa que o intervalo de confiança tem $95 \%$ de chance de estar cobrindo o verdadeiro valor médio do fator $K$ para cada população de dados (anual, estacional ou mensal).

Percebe-se que a amplitude dos intervalos de confiança obtidos é variável, em geral sendo tanto menor quanto maior for o número de observações. Segundo GRAYBILL (1961), um intervalo de confiança muito amplo não dá uma precisão razoável; um intervalo mais estreito que o 
necessario perde informação e recursos. Isto levou à rejeição do valor obtido para o $\mathrm{Km}$ do mês de julho do pVe de Mococa, não se calculando o indice $\mathrm{Kcm}$ correspondente (Tabela 4) e indica que caso se queira uma maior fidedignidade para os valores mensais do fator $k$ é necessário que se aumente o número de anos para a coleta de dados. Para se ter uma idéia do período necessário de observação para atender este propósito, inclusive para os meses menos chuvosos, pode-se analisar as curvas de frequência de chuvas das localidades em questão, a exemplo do que RöMKENS (1985) sugere para as regiões áridas ou semi-áridas.

os valores médios estimados para Ka foram de 0,0113 t.ha.h/ha.MJ.mm para o LRd de Campinas e de 0,0221 t.ha.h/ha.MJ.mm para o PVe de Mococa. Isto é coerente com o fato de o LRd possuir um horizonte B latossolico, que the confere uma maior permeabilidade que o pVe, que possue $B$ textural, pois a erodibilidade de um solo é inversamente proporcional à sua permeabilidade.

Contrariando a literatura oriunda da região temperada do globo, que atesta uma maior erodibilidade nas épocas em que o solo se encontra mais úmido, os valores médios para Ke foram menores de outubro a março do que de abril a setembro para os dois solos estudados.

Quanto aos valores médios para $\mathrm{Km}$, ressalvadas as 1 imitações fiduciais ja discutidas, atingiram um máximo em outubro e um mínimo em agosto para o LRd de Campinas e um máximo em maio e um mínimo em fevereiro para o pve de Mococa. 
Estes valores máximo e mínimo de $\mathrm{Km}$ para o LRd de Campinas não acompanham a tendência dos valores de ke anteriormente comentada.

Passando para as Tabelas 5 e 6 , verifica-se que os valores de $\mathrm{Ka}, \mathrm{Ke} e \mathrm{Km}$ estimados pelo segundo método citado são, em sua maioria, maiores que os encontrados nas tabelas 3 e 4, sendo exceções o Ke de abril a setembro e os $\mathrm{Km}$ de julho, outubro, novembro, fevereiro, abril e maio para o LRd de Campinas. Não se detecta a mesma tendência de erodibilidade maior na época mais seca do ano para os dados de Mococa, não havendo, neste caso, uma diferença expressiva entre as estações. E o indice Kce para o LRd de Campinas aproximou-se bastante do anteriormente obtido para outubro a março foi menor para abril a setembro.

Tanto os valores de $\mathrm{Km}$ como os dos $\mathrm{Kcm}$ correspondentes variaram em relação aos das Tabelas 3 e 4, at ingindo um máximo em junho e coincidentemente um mínimo em agosto para o LRd de Campinas e um máximo em junho e um mínimo em setembro para o pve de Mococa.

Confirma-se no período estudado a tendência estacional da precipitação pluvial e o fato de a erosividade da chuva-enxurrada (índice $\mathrm{EI}_{30}$ ) ser em média maior de outubro a março, perfazendo $78,54 \%$ do seu total anual em Campinas e $84,98 \%$ em Mococa para esta estação. Já os desvios padrão dos dados mensais de precipitação pluvial total, do índice $\mathrm{E}_{30} \mathrm{e}$ das perdas de solo foram, por diversas vezes, maiores que as próprias médias, o que traduz uma grande variabilidade de 
condições para cada ano considerado.

Comparando as Figuras 4 e 5 percebe-se mais semelhança entre os graficos relativos ao pVe de Mococa. para o LRd de Campinas há uma certa semelhança nas tendências dos gráficos, mas o da Figura 4 realça maiores oscilações em relação ao referencial Ka. Nas duas figuras os solos estudados apresentam comportamento diverso, por vezes opostos; por um lado isto pode ser reflexo do regime diferenciado de drenagem, tanto interna como externa, de cada solo; por outro, apesar da semelhança nos valores médios anuais de EI 30 para oeríodo em questão, tratam-se de dois locais diferentes, o que dificulta o aprofundamento desta comparação.

Anal isando os dois métodos de estimativa do fator $K$, nota-se que há vantagens na utilização do primeiro, que o faz através da regressão linear simples. A regressão 1 inear é feita a partir de pares de dados de perdas de solo e do indice $\mathrm{EI}_{30}$, o que impede o mascaramento de alguns dados como ocorre no segundo método. Também, além dos testes estatisticos de significância, é possivel avaliar a fidedignidade dos valores médios estimados para $\mathrm{K}$ através dos intervalos de confiança; pode-se estabelecer um nível mínimo para esta fidedignidade e, com base nisto, decidir pela continuação ou não da coleta de dados, que é trabalhosa e cara e deve ser executada para os solos mais representativos da base geográfica de estudo. Só então seria recomendável o ajuste de curvas, como o realizado por MUTCHLER \& CARTER 
36.

(1983), que possibilitaria novas interpretações e desdobramentos na análise e aplicação prática da variação da erodibilidade do solo durante o ano.

o segundo método, utilizado por MUTCHLER \& CARTER (1983) e por WALL et al. (1988), que se baseia na divisão $\Sigma A / \Sigma \mathrm{EI}_{30}$, poderia ser considerado como um substituto temporário do primeiro método, até que estimativas mais confiaveis fossem obtidas.

A partir deste trabalho já se pode, a nível de pesquisa, e com os solos e locais investigados, atendet às recomendações feitas por MUTCHLER \& MURPHREE (1985) para uma EUPS modificada, na qual se utiliza a aproximação do fator C em subfatores. De acordo com MUTCHLER et a1. (1982), para a modelagem contínua, em contraste com a estimativa média anual, estes subfatores seriam melhor considerados numa base temporal definida, como a mensal por exemplo, ao invés de considerar-se os estádios culturais, que variam com as diferentes culturas e climas.

Segundo LAFLEN (1982), originalmente se aceitava o conceito de que a erodibilidade de um solo era independente de outros fatores envolvidos na erosão. Porém, conforme YOUNG et al. (1990), o fator $k$ da EuPS é um parâmetro que representa uma reação integrada do solo a um grande número de processos erosivos e hidrológicos, tais como a desagregação e o transporte pelo impacto da gota de chuva e escorrimento superficial, a deposição localizada devida à topografia e a rugosidade induzida pelo cultivo e a infiltração da água para 
dentro do perfil. Há também uma percepção crescente de que efeitos temporais desempenham um papel significativo modificando tais processos.

$$
\text { RÖMKENS (1985) apresentou uma série de sugestões }
$$
para melhorar as estimativas do fator $K$ para a Eups que ainda precisam ser testadas e, mesmo nos modelos mais recentes, como se depreende de YOUNG et al. (1990) e MEYER \& HARMON (1992), as variações temporais da erodibilidade do solo são de difícil avaliação e continuam desafiando uma abordagem mais explicativa do fenômeno. Portanto, as pesquisas nesta área estão longe de ser esgotadas. 
38 .

\section{CONCLUSÕES}

Conforme a análise e interpretação dos resultados obtidos no presente trabalho, enumeram-se as seguintes conclusões:

1. A erodibilidade é variável através do ano para as condições de solo e clima testadas.

2. Eossível estimar valores estacionais e mensais, estatisticamente confiácis, para o fator $K$ da EUPS.

3. A tendência estacional detectada é para valores de $K$ maiores na estação mais seca do ano.

4. O comportamento da variação mensal da erodibilidade é diferenciado para solos com horizonte $B$ latossolico e solos com horizonte B textural.

5. O método preferencial para se estimar o fator $K$ da EUPS, inclusive para períodos menores que um ano, é o que utiliza a regressão linear simples entre as perdas de solo, como variável dependente, e o índice de erosividade da chuvaenxurrada, como variável independente.

6. o perfodo necessário de duração dos registros e coleta de dados, para avaliar tendências de longo prazo na erodibilidade do solo, é variável em função da escala temporal com que se estiver trabalhando, e pode ser definido 
39.

pela amplitude desejada dos intervalos de confiança para os valores médios de $K$. 
40 .

\section{REFERENCIAS BIBLI OGRAF ICAS}

ALBERTS, E.E.; LAFLEN, J.M.; SPOMER, R.G. Between year variation in soil erodibility determined by rainfall simulation. Transactions of the ASAE, St. Joseph, 30(4): $982-7,1987$

BERTONI, J. Sistemas coletores para determinação de perdas por erosão. Bragantia, Campinas, 9: 147-55, 1949.

BERTONI, J . \& LOMBARDI NETO, F. Conservação do solo. São Paulo, fcone, 1990. 355p.

BERTONI, J.; LOMBARDI NETO, F.; BENATTI JR., R. Equação de perdas de solo. Campinas, Instituto Agronômico do Estado de São Paulo, 1975. 25p. (IAC, Boletim técnico, 21)

BORAH, D.K. \& ASHRAF, M.S. Modeling storm runoff and sediment with seasonal variations. Transactions of the ASAE, St. Joseph, 33(1): 105-10, 1990. 
CARvalho, M.P. Erosividade da chuva: distribuição e correlação com as perdas de solo de Mococa-sP. Piracicaba, 1987. 140p. (Mestrado-Escola Superior de Agricultura "Luiz de Queiroz"/USP).

CARVAlHo, M.P. Fator erosividade da chuva-enxurrada para chuvas individuais do Estado de São Paulo. Botucatu, 1992. 96p. (Doutorado-Faculdade de Ciências Agronômicas do Campus de Botucatu/UNESP).

CARVALHO, M.P.; LOMBARDI NETO, F.; VASQUES FILHO, J.; CATANEO, A. Indices de erosividade da chuva correlacionados com as perdas de solo de um Podz6lico Verme lho-Amarelo eutrofico textura argilosa/muito argilosa de Mococa(SP): primeira aproximação do fator erodibilidade do solo. Revista Brasileira de Ciência do Solo, Campinas, $13: 237-42,1989$.

COOTE, D.R.; MALCOLM-MCGOVERN, C.A.; WALL, G.J.; DICKINSON, W.T.; RUDRA, R.P. Seasonal variation of erodibility indices based on shear strength and aggregate stability in some Ontario soils. Canadian Journal of Soil Science, Ottawa, 68: $405-16,1988$.

DANGLER, E.W. \& EL-SWAIFY, S.A. Erosion of selected Hawaii soils by simulated rainfall. Soil science society of America Journal, Madison, 40:769-73, 1976. 
DANGLER, E.W.; EL-SWAIFY, S.A.; AHUJA, L.R.; BARNETT, A.P. Erodibility of selected Hawai soils by rainfall simulation. Berkeley, USDA/Agricultural Research Service/Western Region, 1976. 113p. (USDA. ARS-W-35).

DENARDIN, J.E. Erodibilidade do solo estimada por meio de parâmetros físicos e químicos. Piracicaba, 1990. 113 p. (Doutorado - Escola Superior de Agricultura "Luiz de Queiroz"/USP).

FOSTER, G.R.; MCCOOL, D.K.; RENARD, K.G.; MOLDENHAUER, W.C. Conversion of the universal soil loss equation to SI metric units. Journal of soil and water conservation, Ankeny, 36(6): 355-9, 1981 .

GRAYBLLL, F.A. An introduction to linear models. New York, McGraw-Hil1 Book, 1961. v.1. 463p. (McGraw-Hill in Probability and statistics).

HOFFMANN, R. \& VIEIRA, S. Análise de regressão; uma introdução à econometria. São Paulo, HUCITEC-EDUSP, 1977. 339p.

IMESON, A.C. \& VIS, M. Seasonal variations in soil erodibility under different land-use types in Luxembourg. Journal of Soil science, oxford, 35: 323-31, 1984. 
KIRBY, P.C. \& MEHUYS, G.R. Seasonal variation of soil erodibilities in southwestern Quebec. Journal of Soil and Water Conservation, Ankeny, 42: 211-5, 1987.

LAFLEN, J.M. Special problems of the USLE: soil erodibility (K). In: WORKSHOP ON ESTIMATING EROSION AND SEDIMENT YIELD ON RANGELANDS, Oakland, 1982. Proceedings. Washington, USDA, 1982. p.63-72. (USDA. ARM-W-26).

LAL, R. Erodibility and erosivity. In: LAL, R., ed. Soil erosion research methods. Ankeny, Soil and Water Conservation Society, 1988. cap.7, p.141-60.

LOMBARDI NETO, F. Rainfall erosivity - its distribution and relationship with soil loss at Campinas, Brasil. West Lafayette, 1977. 53p. (M.S. - Purdue University).

LOMBARDI NETO, F. Universal Soil Loss Equation (USLE), runoff erosivity factor, slope length exponent, and slope steepness for individual storms. West Lafayette, 1979. 128p. (Ph. -D. - Purdue University).

MCISAAC, G.F. \& MITCHELL, J.K. Temporal variation in runoff and soil loss from simulated rainfall on corn and soybeans. Transactions of the ASAE, St. Joseph, 35(2): $465-72,1992$. 
MEYER, L.D. \& HARMON, W.C. Soil erosion varies during the crop year. Transactions of the ASAE, St. Joseph, 35(2): $459-64,1992$.

MUTCHLER, C.K. \& CARTER, C.E. Soil erodibility variation during the year. Transactions of the ASAE, St. Joseph, $26(4): 1.102-4,1.108,1983$.

MUTCHLER, C.K. \& MURPHREE, C.E. Experimentally derived modification of the USLE. In: EL-SWAIF, S.A.; Moldenhauer, W.C.; Lo, A., ed. Soil erosion and conservation. Ankeny, Soil Conservation society of America, 1985. cap.48, p.523-7.

MUTCHLER, C.K.; MURPHREE, C.E.; McGREgOR, K.C. Subfactor method for computing $C$ factors for continuous cotton. Transactions of the ASAE, St. Joseph, 25(2): 327-32, 1982 .

MUTCHLER, C.K.; MURPHREE, C.E. ; MCGREGOR, K.C. Laboratory and field plots for soil erosion studies. In: LAL, R., ed. Soil erosion research methods. Ankeny, Soil and Water Conservation Society, 1988 . cap. 2, p.9-36.

ROMKENS, M.J.M. The soil erodibility factor: a perspective. In: EL-SWAIFY, S.A.; MONDENHAUER, W.C.; LO, A., ed. Soil erosion and conservation. Ankeny, Soil Conservation Society of America, 1985. cap.42, p.445-61. 
SPIEGEL, M.R. Estatística. Rio de Janeiro, Ao Livro Técnico, 1968 . $580 \mathrm{p}$.

WALL, G.J.; DICKINSON, W.T.; RUDRA, R.P.; COOTE, D.R. Seasonal soil erodibility variation in southwestern Ontario. Canadian Journal of Soil science, otawwa, 68: $417-24,1988$.

WISCHMEIER, W.H. Upslope erosion analysis. In: SHEN, H.W., ed. Environmental impact on rivers. Fort Collins, Colorado state University, 1972. cap.15, 26p.

WISCHMEIER, W.H. Use and misuse of the universal soil loss equation. Journal of Soil and Water Conservation, Ankeny, $31(1): 4-9,1976$.

WISCHMEIER, W.H. \& MANNERING, J.V. Relation of soil properties to its erodibility. Soil science society of America Proceedings, Madison, 33(1): 131-7, 1969.

WISCHMEIER, W.H. \& SMITH, D.D. Predicting rainfall erosion losses from cropland east of the Rocky Mountains; guide for selection of practices for soil and water conservation. Washington, USDA, 1965. 47p. (USDA. Agriculture Handbook, 282). 
WISCHMEIER, W.H. \& SMITH, D.D. Predicting rainfall exosion losses; a guide to conservation planning. Washington, USDA, 1978. 58p. (USDA. Agriculture llandbook, 537).

YOUNG, R.A.; ONSTAD, C.A.; MCCOOL, D.K.; BENOIT, G.R. Temporal changes in soil erodibility. In: NATURAL RESOURCES MODELING SYMPOSIUM, pingree park, 1983. Proceedings. Washington, USDA, 1985. p.442-5. (USDA. ARS-30)

YOUNG, R.A.; RÖMKENS, M.J.M.; McCOOL, D.K. Temporal variations in soil erodibility. In: BRYAN, R.B., ed. Soil erosion; experiments and models. Cremlingen Destedt, Catena Verlag, 1990. p.41-53. (Catena Supplement, 17 ). 